\title{
Rancang Bangun Rekonstruksi 3D Dengan Kinect Xbox 360
}

\author{
Trisni Wahyu Ningtias ${ }^{1}$, Koko Joni ${ }^{1}$, Riza Alfita ${ }^{1}$ \\ ${ }^{1}$ Program Studi Teknik Elektro, Fakultas Teknik, Universitas Trunojoyo Madura \\ Jalan Raya Telang, Kabupaten Bangkalan, Jawa Timur 69162 \\ E-mail: trisniwahyu03@gmail.com
}

\begin{abstract}
ABSTRAK
Abstrak - Perkembangan teknologi yang semakin pesat dan efektif membawa dampak pada bidang teknologi. Salah satunya adalah pemindaian objek dengan menggunakan komputer. Pemindaian objek merupakan teknologi yang menggabungkan antara hardware untuk melihat objek dan software untuk mengolah data yang telah diterima oleh hardware. Proses manufaktur tradisional tanpa pemindaian 3D meliputi desain, analisis dan uji prototipe membutuhkan waktu yang sangat lama dan secara ekonomis mahal. Sedangkan dengan pemindaian 3D dinilai mampu lebih efisien dan praktis. Penelitian ini dilakukan untuk mempermudah rekonstruksi melalui proses pemindaian 3D dengan memanfaatkan sensor pada kamera Kinect 360. Objek akan secara langsung dipindai dengan kamera secara menyeluruh $360^{\circ}$ yang dibagi menjadi 8 kali potret untuk mendapatkan data setiap sisinya. Hasil yang diperoleh akan diolah oleh sistem untuk selanjutnya diproses menjadi objek 3D. Proses pengambilan data objek menggunakan software Eclipse sedangkan pemutaran objek menggunakan motor stepper yang dikontrol arduino. Berdasarkan hasil pengujian dari penelitian yang telah dilakukan diketahui bahwa sensor infrared pada kamera Kinect kurang maksimal dalam memantulkan cahaya kembali pada benda yang memiliki permukaan tidak rata. Namun sebaliknya sensor bekerja dengan baik pada benda yang memiliki permukaan rata.
\end{abstract}

Kata kunci: objek, pemindaian, sensor, kamera, Kinect Xbox

Copyright CO 2019 Universitas Muhammadiyah Jember.

\section{PENDAHULUAN}

Dewasa ini perkembangan teknologi yang kian canggih dan kompetitif membawa pengaruh pada bidang ilmu pengetahuan. Salah satu yang utama yakni pemindaian objek menggunakan perangkat komputer. Pemindaian objek merupakan perpaduan antara teknologi hardware untuk menangkap visual objek dan software sebagai sarana pengolah data yang diterima oleh hardware tersebut. Hasil visualisasi objek dua dimensi (2D) yang diterima dari kamera akan secara otomatis diolah oleh software menjadi objek tiga dimensi (3D).

Scanning $3 D$ adalah proses menangkap informasi digital tentang bentuk objek dengan peralatan yang menggunakan kamera untuk mengukur jarak antara scanner dan objek. Hal ini dapat digunakan untuk kebutuhan modifikasi, manufaktur, monitoring yang dibantu komputer, atau hanya menyimpan informasi bentuk objek untuk kebutuhan di masa depan. Pada proses manufaktur tradisional terdiri dari beberapa tahapan yang meliputi desain, analisis dan uji prototipe. Proses ini dinilai memerlukan waktu yang cukup lama. Selain itu jika ditinjau dari segi ekonomi memerlukan biaya yang tidak sedikit. Apabila terdapat kesalahan pada tahap analisis hasil uji maka perlu dilakukan pengulangan proses awal yaitu desain. Hal tersebut tidak berlaku pada metode scanning $3 D$ karena proses desain, analisis dan simulasi dapat dieksekusi secara multitasking, terintegrasi dan sangat cepat. Kemungkinan error yang terjadi dapat langsung dianalisa dan diperbaiki. Setelah perbaikan selesai dapat dilanjutkan ke tahap proses pengujian dan prototipe. $3 D$ scanning juga merupakan salah satu komponen dalam membangun sistem manufaktur CIM (Computer Integrated Manufacturing [1].

Berdasarkan permasalahan tersebut, maka dilakukan sebuah penelitian mengenai pemodelan objek menggunakan $3 D$ scanning untuk memudahkan dalam memvisualkan objek secara lebih cepat untuk dunia manufaktur. 


\section{KAJIAN PUSTAKA}

\subsection{Objek 3D}

3D atau 3 dimensi merupakan sebuah objek yang memiliki ukuran panjang, lebar dan tinggi berbentuk. Dalam matematika dan fisika 3d biasa disebut dengan bangun ruang. Namun ternyata 3D memiliki cakupan yang sangat luas termasuk pada bidang grafis, seni, animasi dan computer. Dimensi spasial menunjukkan bahwa tertdapat suatu titik koordinat kartesius X, Y dan Z pada objek tiga dimensi. Sedangkan pemodelan meupakan pembentukan suatu benda atau objek. Berdasarkan objek dan basisnya tahap perancangan diproses menggunakan komputer. Melalui konsep dan proses desain, keseluruhan objek dapat diperlihatkan secara tiga dimensi, sehingga disebut sebagai pemodelan tiga dimensi [2].

\subsection{Citra Digital}

Citra merupakan intensitas fungsi 2 dimensi dari $f(x, y)$, dimana $x$ dan $y$ merupakan nilai dari koordinat spasial sedangkan $f$ pada titik $(x, y)$ merupakan tingkatan kecerahan citra pada titik tertentu. Citra digital merupakan hasil pengolahan citra yang dilakukan menggunakan alat bantu komputer. Jumlah bit yang digunakan untuk merepresentasikan setiap piksel pada masing-masing komputer mempengaruhi resolusi warna pada citra digital yang dihasilkan. Pada umumnya digunakan nilai 8-bit untuk merepresentasikan citra, 0 untuk hitam dan 255 untuk putih. Berikut merupakan jenis dari citra digital:

\section{a. Black and White}

Setiap piksel pada citra digital black and white (grayscale) memiliki warna yang berbeda mulai dari warna putih hingga hitam. Tingkatan nilai warna mengisyaratkan bahwa setiap piksel dapat diwakili oleh 8 bit, atau 1 byte. Rentang warna pada citra black and white sangat cocok digunakan untuk pengolahan file gambar. Black and white sebenarnya merupakan hasil rata-rata dari warna gambar, dengan demikian maka persamaannya dapat dituliskan sebagai berikut :

$$
I_{B W}(x, y)=\frac{I_{R}(x, y)+I_{G}(x, y)+I_{B}(x, y)}{3}
$$

Pada persamaan diatas diketahui bahwa $I_{R}(x, y)=$ nilai pixel red titik $(\mathrm{x}, \mathrm{y}), I_{G}(x, y)=$ nilai pixel green titik $(\mathrm{x}, \mathrm{y}), I_{B}(x, y)=$ nilai pixel blue titik $(\mathrm{x}, \mathrm{y})$, sedangkan $I_{B W}(x, y)=$ nilai pixel black and white titik $(\mathrm{x}, \mathrm{y})$.

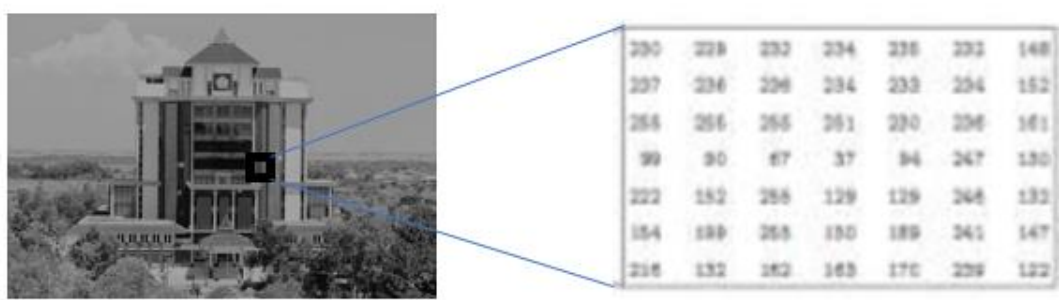

Gambar 1. Citra Black \& White

\section{b. Citra RGB}

Citra RGB (Red, Green, Blue) adalah komponen warna pokok pada suatu gambar. Setiap titik piksel mempunyai warna tertentu yaitu merah (Red), hijau (Green), dan biru (Blue). Masing-masing warna mempunyai nilai ambang batas atau range $0-255$, maka total keseluruhan dari seluruh warna adalah $2553=16.581 .375(16 \mathrm{~K})$ variasi warna pada gambar. Pada setiap piksel memiliki tiga matriks yang berisi warna merah, hijau, biru [3]. 


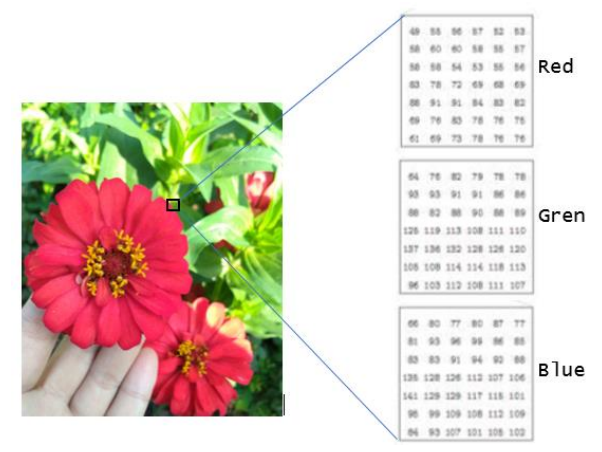

Gambar 2 Citra RGB

\subsection{Pengolahan Citra (Image Processing)}

Pengolahan citra yang diproses menggunakan komputer awalnya dilakukan pengubahan model citra menjadi beberapa bentuk besaran yang berbeda. Besaran tersebut terdiri dari bagian tititk-titik citra yang memiliki tingkatan keabuan. Titik citra tersebut jika diinputkan pada layar monitor akan mengisi sebuah tempat yang biasa disebut piksel. Berdasarkan kemajuan teknologi komputer terdapat dua tujuan pengolahan citra yaitu:

1. Menyempurnakan nilai citra agar hasil citra dapat menampilkan data dengan jelas. Manusia mengambil peran sebagai pengolah data (human perception).

2. Mencari isi data yang sifatnya unik sebagai ciri pada citra secara numerik. Pada tahap ini komputer melakukan penafsiran pada data yang sudah ada agar dapat dibedakan menjadi data numerik secara lebih jelas [4].

\subsection{Eclipse IDE}

Eclipse merupakan suatu IDE (Integrated Development Environment) yang digunakan untuk proses pengembangan perangkat lunak agar dapat dijalankan di semua platform (platformindependent). Di bawah ini merupakan ciri-ciri dari Eclipse:

a. Multi-platform : Sasaran pada sistem operasi Eclipse sangat beragam meliputi Microsoft Windows, Linux, Solaris, AIX, HP-UX dan Mac OS X.

b. Multi-language : Eclipse umumnya dikembangkan menggunakan bahasa pemrograman Java namun tidak menutup kemungkinan developer menggunakan bahasa pemrograman lain seperti $\mathrm{C} / \mathrm{C}++$, Cobol, Python, Perl, PHP, dan lain sebagainya.

c. Multi-role : Selain telah terintegrasi sebagai pengembangan aplikasi, Eclipse dapat digunakan untuk aktivitas dalam proses pengembangan perangkat lunak seperti dokumentasi, test perangkat lunak, pengembangan web, dan lain sebagainya.

Saat ini Eclipse menjadi salah satu IDE yang banyak digemari para pengembang karena sifatnya yang open source dan gratis. Setiap orang memiliki akses untuk dapat melihat kode pemrograman ini. Selain itu komponen plugin pada Eclipse menjadikannya semakin populer dikalangan penggunanya [5].

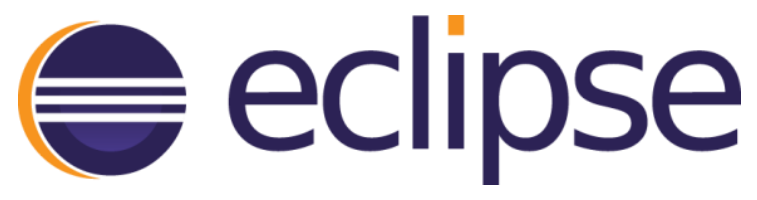

Gambar 3. Logo Eclipse

\subsection{K-Nearest Neighbors}

Metode Nearest Neighbor merupakan salah satu teknik klasifikasi yang berdasarkan kedekatan objek, dengan membandingkan jarak setiap objek. Pendekatan yang digunakan pada Nearest Neighbour sendiri merupakan pendekatan klasifikasi yang mencari semua data latih yang relatif mirip dengan data uji. Kedekatan disini didefenisikan dengan ukuran jarak, misalnya Euclidean. Jarak Euclidean antar dua titik, missal Titik1 $=(x 1, y 1)$ dan Titik2 $=(x 2, y 2)$ adalah : 


$$
\operatorname{Dist}\left(\text { Titik1,Titik2) }=\sqrt{(x 1-x 2)^{2}+(y 1-y 2)^{2}}\right.
$$

\subsection{KD-Tree}

KD-Tree (K-Dimensional Tree) merupakan representasi data multidimensional dalam bentuk binary tree yang bertujuan untuk memisahkan setiap data dalam suatu area tertentu berdasarkan nilai posisinya (Skiena, 2008). Contoh KD-Tree yang disusun dari data $(3,4),(7,2),(2,8)$ dan $(4,10)$ dapat dilihat pada Gambar 4 [6].

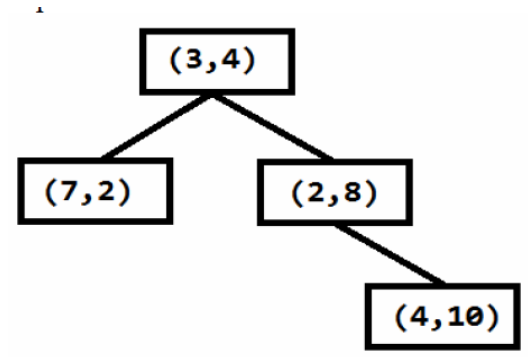

Gambar 4. Contoh KD-Tree

\section{METODE PENELITIAN}

\subsection{Perancangan Perangkat Keras}

Pada tahapan ini dirancang blok diagram cara kerja rekonstruksi 3D Kinect Xbox 360 berbasis mikrokontroler arduimo. Alur proses pengolahan dijelaskan seperti pada gambar 5.

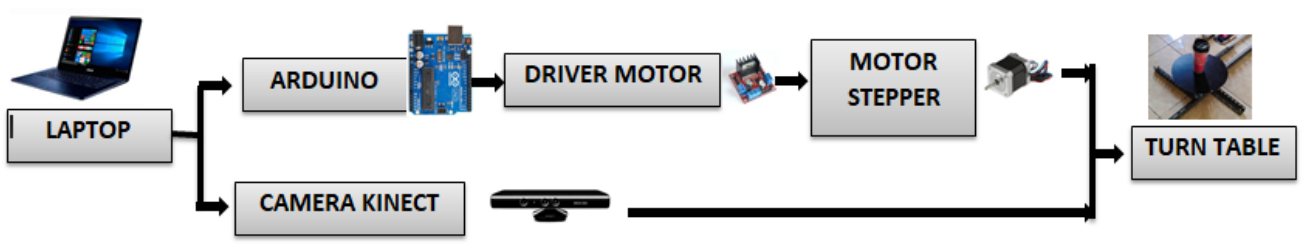

Gambar 5. Blok Diagram Hardware

Dari gambar 5 diketahui bahwa alur proses pengolahan dimulai dari PC yang tersambung ke arduino dan kamera kinect. Arduino sebagai mikrokontroler yang menerima output dari program arduino itu sendiri sedangkan kamera kinect digunakan untuk pengambilan objek gambar. Selanjutnya diantara arduino dan motor stepper dipasang driver sebagai switch berfungsi untuk melewatkan arus tegangan sesuai dengan kebutuhan motor stepper. Motor stepper di sini digunakan sebagai penggerak turntable sekaligus tatakan tempat benda yang akan dicapture dan direkontruksi.

\subsection{Perancangan Software}

Gambar 6 merupakan hasil perancangan GUI Kinect Scan yang digunakan untuk mengambil data objek model. Kinect Scan disusun menggunakan software Eclipse Java yang di dalamnya terdapat dua tombol Nyalakan dan Simpan. Saat tombol Nyalakan ditekan maka tombol akan otomatis menjadi berubah kondisi menjadi aktif low begitu pula sebaliknya. 


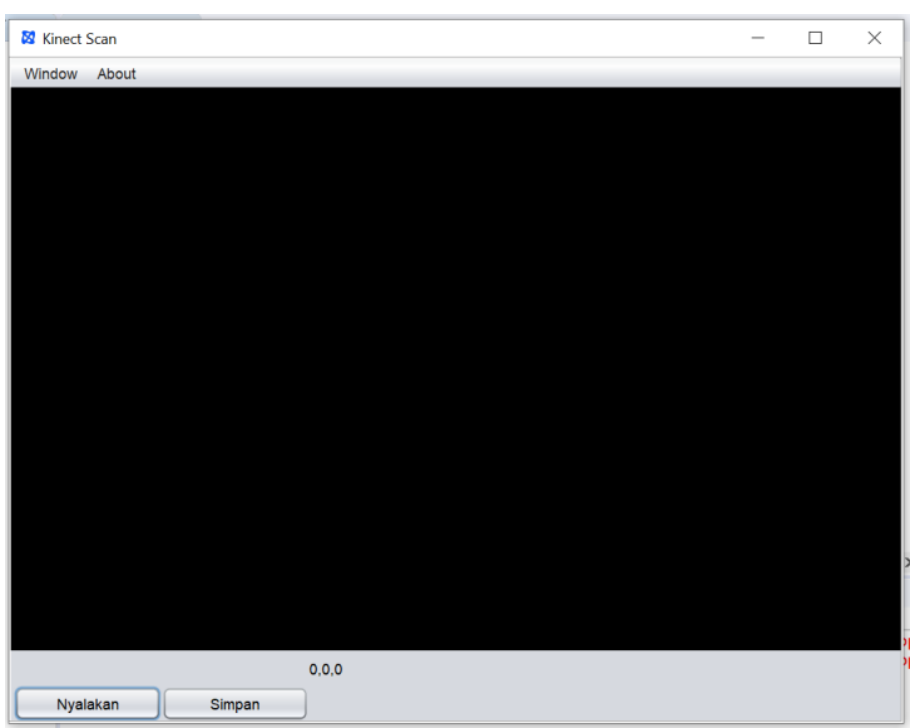

Gambar 6. Tampilan GUI Kinect Scan

\subsection{Skenario Pengujian}

Pengujian kamera Kinect Xbox 360 dilakukan dengan cara menghubungan usb kamera ke port usb pada laptop. Pengujian dilakukan dengan program Eclipse java. Prosedur pengujian yang dilakukan adalah sebagai berikut:

a. Hubungkan usb kamera kinect ke port usb pada laptop dan adaptor kinect ke terminal

b. Buka software Eclipse kemudian jalankan program KinectView dengan menggunakan configuration seperti pada gambar di bawah

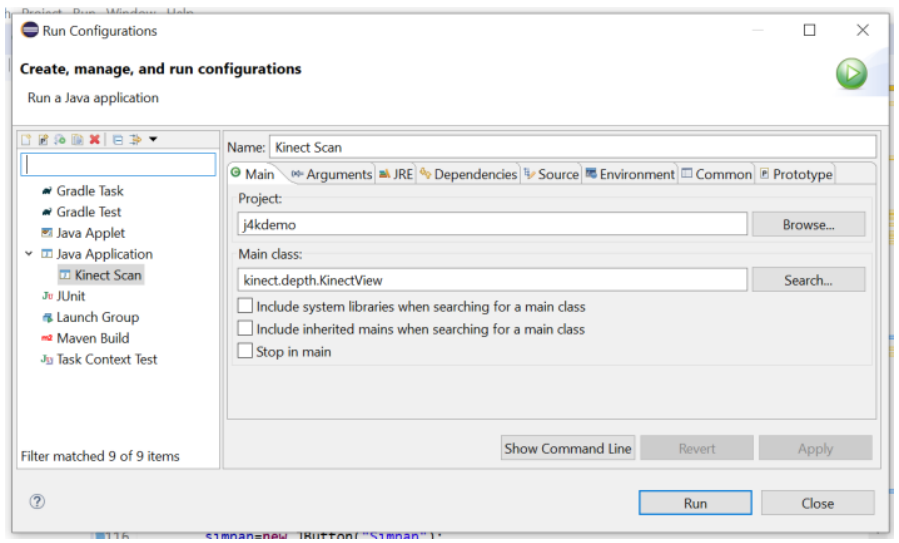

Gambar 7. Konfigurasi Program Kinect Scan

c. Klik tombol nyalakan pada program yang sudah dijalankan

d. Atur dan arahkan kamera ke objek yang akan diambil gambar

e. Pastikan tampilan objek yang tertangkap kamera berwarna putih, jika masih berwarna hitam maka perlu dilakukan pengaturan jarak antara kamera dengan objek. 


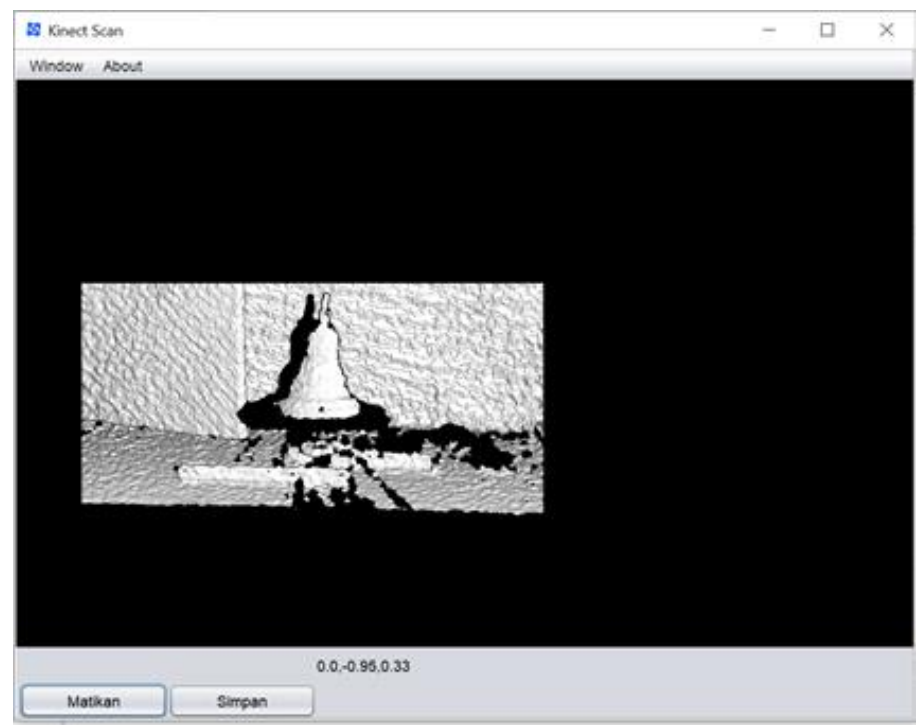

Gambar 8. Tampilan Objek Pada GUI

f. Klik tombol simpan pada aplikasi, program akan menyimpan data depth yaitu depth_1.txt pada directory D: data_kinect

g. Hasil data depth_1.txt yang telah disimpan selanjutnya diimport pada software Blender untuk diproses menjadi data mesh.

h. Saat import file telah berhasil selanjutnya dilakukan proses meshing menggunakan script metode KD-Tree .

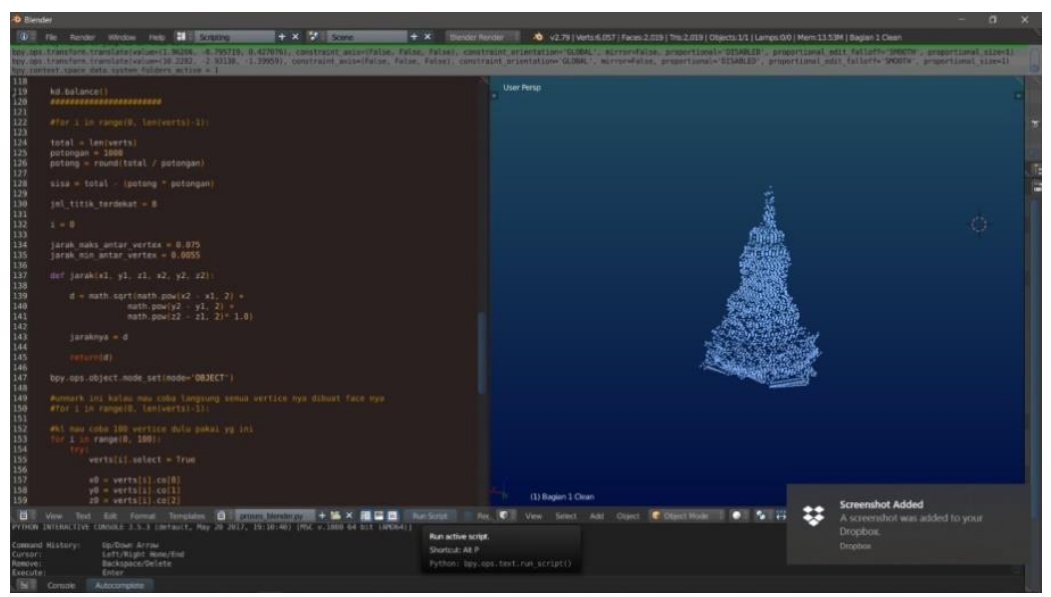

Gambar 9. Proses Meshing Data Depth 
i. Proses meshing menggunakan script metode KD-Tree menghasilkan data mesh.

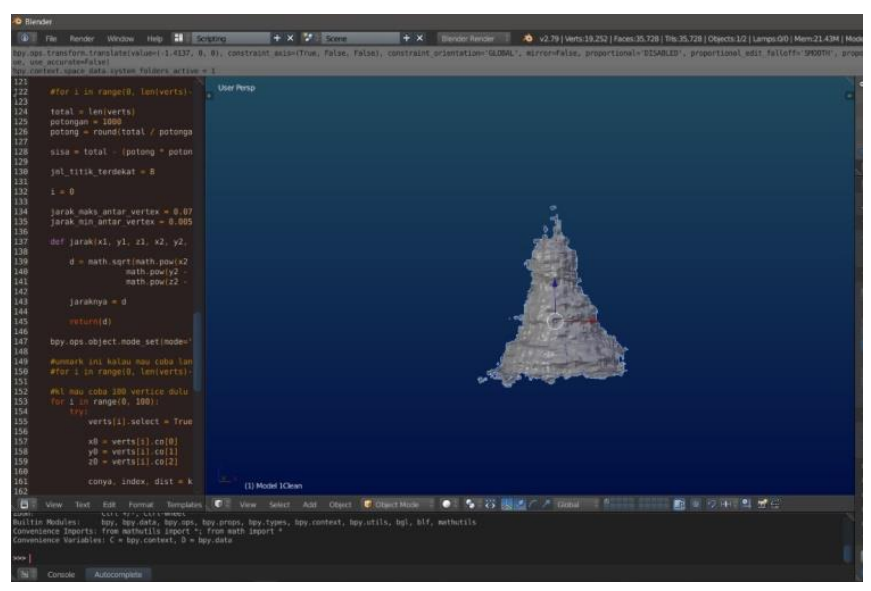

Gambar 10. Hasil Data Depth

j. Proses penggabungan masing-masing hasil mesh sehingga membentuk sebuah patung utuh.

\section{HASIL DAN PEMBAHASAN}

\subsection{Hasil Pengujian}

Tabel 1. Hasil Capture Depth Data dan Hasil Mesh Model

\begin{tabular}{|c|c|c|}
\hline Keterangan & Hasil Depth Data & Hasil Mesh \\
\hline $\begin{array}{l}\text { Capture ke-1 } \\
\text { Sudut pandang } 0^{\circ}-45^{\circ}\end{array}$ & 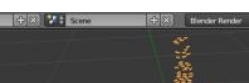 & \\
\hline $\begin{array}{l}\text { Capture ke-2 } \\
\text { Sudut pandang } 46^{\circ}-90^{\circ}\end{array}$ & & \\
\hline
\end{tabular}




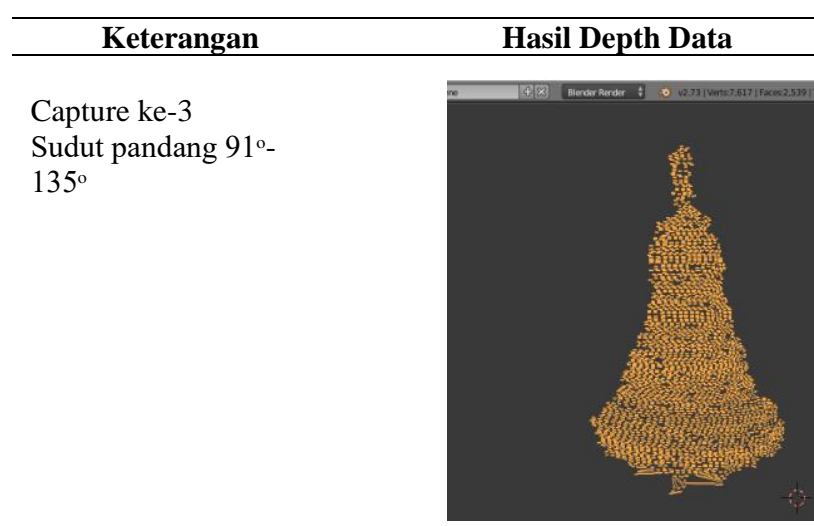

Hasil Mesh

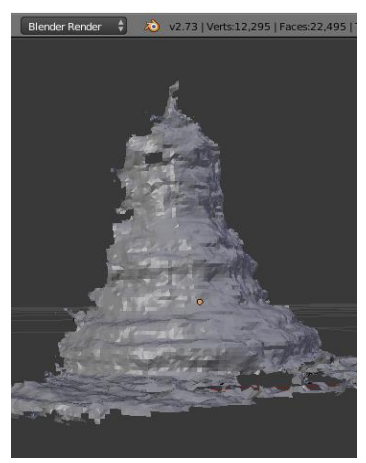

Capture ke-4

Sudut pandang $136^{\circ}-$ $180^{\circ}$
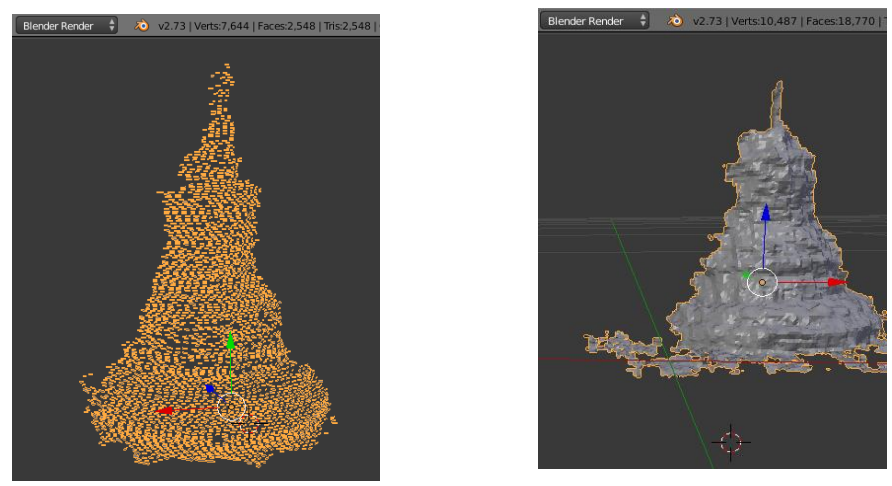

Capture ke-5

Sudut pandang $181^{\circ}$ $225^{\circ}$
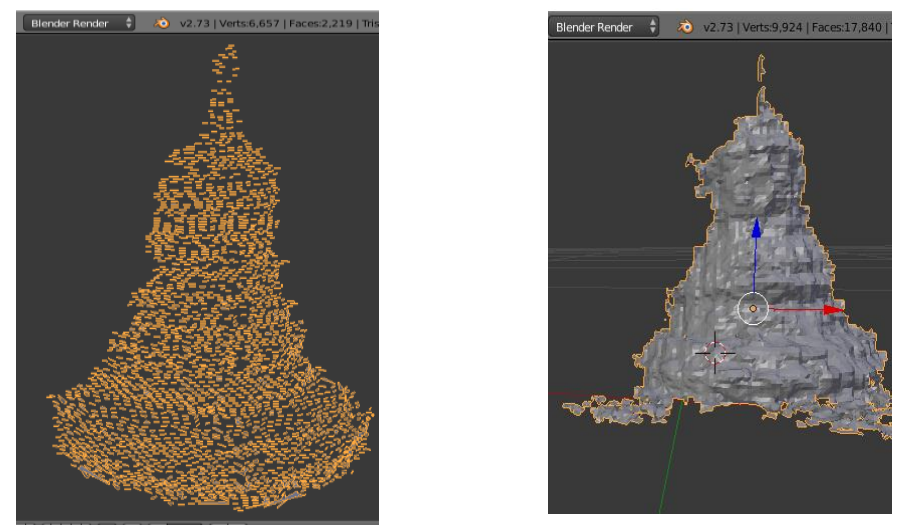

Capture ke-6

Sudut pandang $226^{\circ}-$ $270^{\circ}$

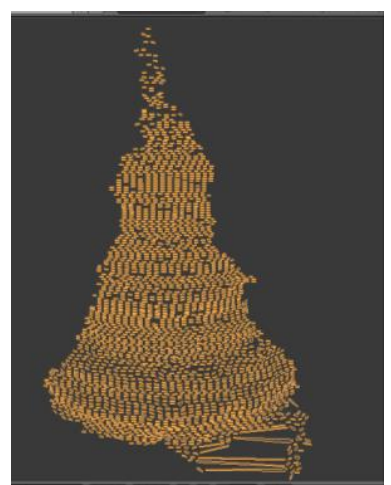

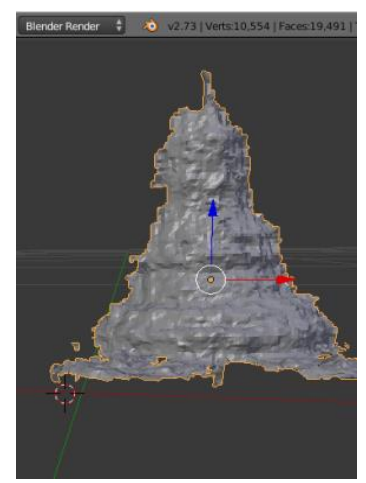




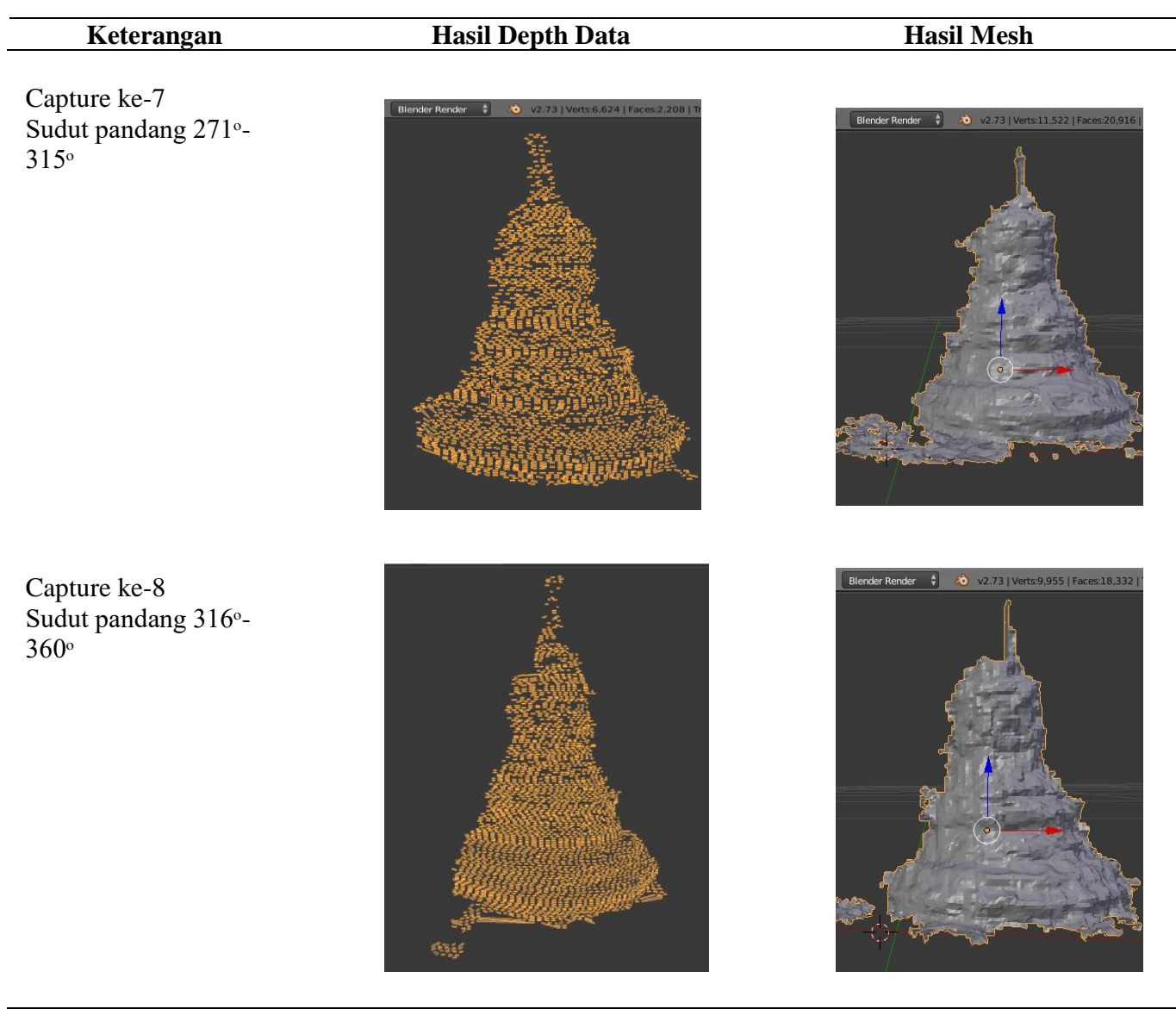

Pada tabel 1 Hasil Capture Depth Data dan Hasil Mesh Data terdapat dua kolom yang terdiri dari delapan kali percobaan berbeda. Masing-masing percobaan merupakan hasil dari sudut pandang setiap $45^{\circ}$ mulai sudut $0^{\circ}$ hingga $360^{\circ}$. Proses capture setiap bagian ditentukan oleh pergerseran sudut motor stepper. Motor stepper akan berrputar sesuai dengan program yang telah dirancang pada software Arduino yang mana pada percobaan dirancang setiap satu kali putaran akan bergeser sebesar $45^{\circ}$.

Pada kolom hasil depth data merupakan representasi dari hasil capture camera kinect yang dilakukan menggunakan software Eclipse Java. Selanjutnya pada kolom hasil mesh data terdapat hasil olahan capture kamera kinect dengan menggunakan metode KD-Tree. Metode ini menproses model capture yang berupa puluhan ribu vertex menjadi sebuah model mesh yang solid. Setiap vertice yang berdekatan akan dikelompokkan oleh sistem pada software Blender berdasakan nilai posisinya sehingga membentuk vertex. Kumpulan vertex-vertex yang telah tersusun akan membentuk sebuah model mesh data. Saat mesh data telah terbentuk maka perlu dilakukan proses cleaning up. Proses tersebut dilakukan untuk membersihkan bagian-bagian yang tidak diinginkan yang berada di sekeliling objek. Percobaan yang dilakukan pada model Patung Borobudur sekilas tampak seperti sama karena memang model ini memiliki permukaan sama. Akan tetapi setiap capturenya merupakan hasil dari delapan sudut pandang berbeda yang mana jika digabungkan menjadi satu akan membentuk sebuah patung utuh. 
Berikut perbandingan model asli dengan hasil rekonstruksi 3D dari dua sudut pandang yang berbeda 1. Model Patung Candi Borobudur

a. Tampak Depan

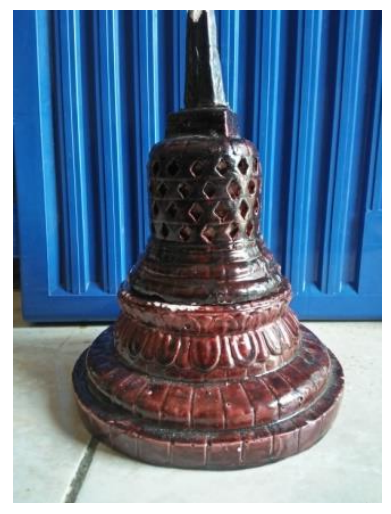

(a)

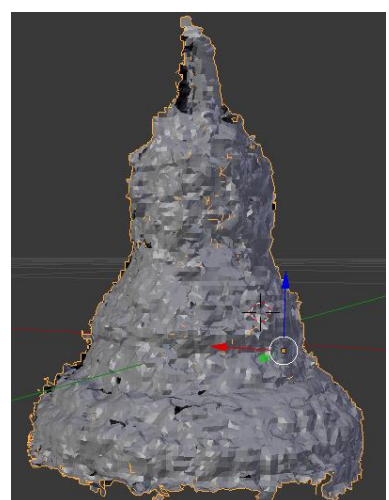

(b)

Gambar 11. (a) Model asli (b) Hasil Rekonstruksi

b. Tampak Atas
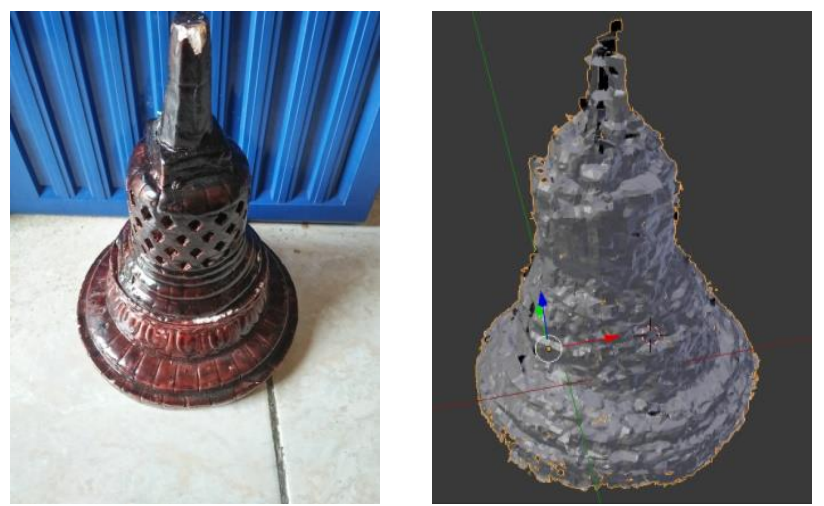

Gambar 12. (a) Model asli (b) Hasil Rekonstruksi

Pada gambar 11 Tampak Depan dan 12 Tampak Atas merupakan hasil percobaan yang menggunakan patung candi borobudur sebagai model objek. Patung tersebut dicapture dan direkonstruksi sesuai dengan langkah-langkah yang telah ditentukan. merupakan hasil depth data dan mesh dari objek model patung candi Borobudur. Model candi memiliki ukuran diameter dasar $17 \mathrm{~cm}$ dan tinggi $23 \mathrm{~cm}$. Proses capture dilakukan sebanyak 8 ( delapan ) kali dengan pergerakan setiap sudut adalah $45^{\circ}$ sehingga diperoleh nilai satu kali rotasi $360^{\circ}$. Posisi dari setiap sudut menghasilkan hasil depth image yang berbeda-beda sehingga hasil mesh yang diperoleh pun berbeda.

Proses capture sebanyak delapan kali berhasil dilakukan dan diperoleh data depth sesuai dengan step pengambilannya. Data depth yang diperoleh bergantung pada kondisi permukaan model yang digunakan. Data tersebut berisi koordinat xyz diproses menggunakan script python agar membentuk triangulasi. Rata-rata waktu yang diperlukan dari setiap model yang dicapture pada proses triangulasi adalah 50menit. Hasil triangulasi tiap capture akan diproses menjadi mesh menggunakan software blender dengan menggunakan script python sehingga membentuk model 3D. Pada objek ini diketahui terdapat lekukan dan lubang-lubang detail candi yang berukuran kecil. Permukaan yang tidak rata tersebut menyebabkan sinar infrared tidak terpantul secara maksimal. Hal tersebut berakibat pada hasil model 3D yang kurang detail sesuai model aslinya. 


\section{KESIMPULAN}

Berdasarkan hasil empat percobaan yang telah dilakukan diperoleh kesimpulan sebagai berikut:

1. Permukaan objek yang akan direkonstruksi berpengaruh pada hasil akhir model 3D.

2. Pada permukaan yang tidak rata, infrared tidak bisa maksimal memantul kembali ke sensor. Sebaliknya pada objek dengan permukaan rata, infrared mampu memantul kembali ke sensor secara maksimal.

3. Semakin kecil ukuran objek yang dicapture maka semakin kecil pula tingkat kemiripan dengan objek aslinya.

4. Detail pada objek yang berukuran kecil dibawah $10 \mathrm{~cm}$ tidak bisa direkonstruksi secara maksimal sehingga menyerupai objek aslinya.

\section{DAFTAR PUSTAKA}

[1] E. Junaidi, Waslaluddin, and L. Hasanah, "Rancang Bangun Scanner 3D Menggunakan Sensor Ultrasonik dengan Tampilan Realtime Berbasis Mikrokontroler," Fibusi J. Online Fis., vol. 3, no. 2, 2015.

[2] P. Dimensi, U. Bangunan, and D. I. Kawasan, "The 3 Dimensional Modeling For Buildings At Puspiptek, Serpong,” J. Ilm. Geomatika, vol. 18, no. 1, pp. 1-8, 2012.

[3] R. Kastaman, Marsetyo, Sunarmani, and A. S. Somantri, "Aplikasi Pengolah Citra d engan Basis Fitur Warna 'RGB' untuk Klasifikasi Buah Manggis (Roni Kastaman dkk.),” J. Bionatura, vol. 10, no. 3, pp. 273-291, 2008.

[4] Jogiyanto Hartono (1989:1), "Bab 2 landasan teori,” Apl. dan Anal. Lit. Fasilkom UI, pp. 4-25, 2006.

[5] M. Abdurrozzaq Almuzakki, "Rancang Bangun Aplikasi Location Based Service Pencarian Lokasi Wisata Di Kota Semarang Berbasis Android,” Dok. karya Ilm., pp. 1-8, 2013.

[6] Y. Lukito, J. Wahidin, and S. Husodo, “Analisis Kinerja Struktur Data Kd-Tree Pada Metode K-Nearest Neighbors Kata kunci : KD-Tree, K-Nearest Neighbors, Array,” Riau J. Comput. Sci., vol. 2, no. 2, pp. 1-6, 2016.

\section{BIOGRAFI PENULIS}

Penulis bernama Trisni Wahyu Ningtias yang lahir di Madiun pada tanggal 08 Oktober tahun
1996. Saat ini sedang mengambil pendidikan S1 di prodi Teknik Elekro Universitas
Trunojoyo Madura. Penelitian yang dilakukan oleh penulis yakni tentang pemodelan 3D
dengan menggunakan Kinect. Penulis dapa dihubungi melalui email:
trisniwahyu03@ @mail.com

